\title{
Conditioned object preference: an alternative approach to measuring reward learning in rats
}

\author{
Bruce C. Kennedy, ${ }^{1}$ Maulika Kohli, ${ }^{2}$ Jamie J. Maertens, ${ }^{2}$ Paulina S. Marell, ${ }^{3}$ and \\ Jonathan C. Gewirtz ${ }^{2}$ \\ ${ }^{1}$ Department of Neuroscience; ${ }^{2}$ Department of Psychology, University of Minnesota, Minneapolis, Minnesota 55455, USA; \\ ${ }^{3}$ Department of Neurobiology, University of Pittsburgh, Pittsburgh, Pennsylvania 15213, USA
}

\begin{abstract}
Pavlovian conditioned approach behavior can be directed as much toward discrete cues as it is toward the environmental contexts in which those cues are encountered. The current experiments characterized a tendency of rats to approach object cues whose prior exposure had been paired with reward (conditioned object preference, COP). To demonstrate the phenomenon, rats were conditioned to associate cocaine or saline with two different objects. Rats acquired a preference, assessed using investigation times directed toward each object, for the cocaine-paired object following conditioning. Furthermore, high levels of object investigation during cocaine conditioning predicted stronger preferences for the cocaine-paired object in the test phase. Conditioned approach diminished across extinction but was reinstated through a priming injection of cocaine. To determine whether preferences are affected by reward value, rats were conditioned using three objects paired with 0,5 , or $20 \mathrm{mg} / \mathrm{kg}$ of cocaine. This produced object preferences in the post-test that scaled with cocaine dose used for conditioning. Finally, we explored whether contextual cues modulate expression of COP by testing rats for renewal of cocaine seeking. When conditioning was conducted in one context and extinction training in a second context, COP was renewed when the rats were retested in the original context. Thus, conditioned object preferences are readily acquired, easily measured, and amenable to a number of standard Pavlovian conditioning manipulations. This task promises to become a valuable addition to the panoply of behavioral tools available to test mechanisms underlying adaptive and maladaptive reward processing.
\end{abstract}

[Supplemental material is available for this article.]

Conditioned approach toward cues previously paired with reward (Pavlov 1932; Miller 1961; Brown and Jenkins 1968) is an evolutionarily conserved behavior observed in many species including Drosophila, zebrafish, mice, rats, and primates (D'amato and Buckiewicz 1980; Spyraki et al. 1982; Ninkovic and Bally-Cuif 2006; Kaun et al. 2011; Cunningham and Zerizef 2014). This behavioral tendency forms the basis of the conditioned place preference (CPP) task (Beach 1957), the most commonly used measure of positive reinforcement in rodents. In this paradigm, a rewarding stimulus such as a drug, food, or a conspecific is paired with a distinct environment or context. The efficacy of the reinforcer can be quantified by measuring the animal's preference for the context paired with the reinforcer compared with an alternative (control) context in a choice test. Over the past few decades, the use of the CPP paradigm has increased steadily, with over a thousand cited uses of the task between 1998 and 2007 (Tzschentke 2007).

The popularity of the CPP task-especially in the study of drug addiction - may be attributed to the many advantages of this approach (see Schechter and Calcagnetti 1993; Bardo and Bevins 2000). These include control over the drug dose and timing of delivery, low cost of materials, and the capacity for high throughput. Additionally, CPP is appealing for its ethological relevance because environmental cues play an instrumental part in compulsive human behaviors including habitual drug use. For example, smokers experienced cigarette cravings when exposed to laboratory replicates of environments commonly associated

\section{Corresponding author: bruceck2@gmail.com}

Article is online at http://www.learnmem.org/cgi/doi/10.1101//m.042598.116. with smoking such as bars or coffee shops, even in the absence of more explicit smoking cues like ashtrays or cigarettes (Conklin 2006). Similarly, alcoholics shown images depicting social or physical environments associated with alcohol consumption exhibited elevated arousal and reduced startle responses, even when images lacked explicit alcohol cues (Nees et al. 2012).

Nevertheless, conditioned behavior may also be controlled by more discrete cues. In the case of drug addiction, these include the presence of fellow drug users and access to specific objects including drug paraphernalia. For this reason, objects commonly serve as drug-related stimuli in human and nonhuman primate imaging studies. Images or replicates of the drug (e.g., cigarettes, cocaine powder) or drug-related paraphernalia, presented alone or as part of a stimulus complex, reliably increase emotional and physiological responses in drug users and induce craving for a variety of drugs of abuse including nicotine (Franklin et al. 2009; Engelmann et al. 2011; Wilson et al. 2012), marijuana (Filbey et al. 2009), cocaine (Grant et al. 1996), alcohol (Myrick et al. 2008), and opioids (Powell et al. 1993).

The few studies that have utilized object cues within a Pavlovian conditioned preference procedure have revealed that animals approach objects previously paired with rewards. Bassareo and Di Chiara (1997) found that rats oriented toward

(C) 2016 Kennedy et al. This article is distributed exclusively by Cold Spring Harbor Laboratory Press for the first 12 months after the full-issue publication date (see http://learnmem.cshlp.org/site/misc/terms.xhtml). After 12 months, it is available under a Creative Commons License (AttributionNonCommercial 4.0 International), as described at http://creativecommons. org/licenses/by-nc/4.0/. 
and made contact with an empty box that predicted access to highly palatable food. After the box was repeatedly presented in the absence of food, rats ceased to approach the box, suggesting that the approach behavior could be extinguished. A more recent study found that female rats would preferentially explore chambers containing scented objects paired with either amphetamine administration or opportunities for paced mating versus a chamber containing a neutral control object (Guterl et al. 2015). Thus, similarly to environmental cues, objects are both integral to drug use in human addicts and elicit conditioned approach behavior in rodent models of drug-seeking behavior.

The adoption of object cues in studies of positive reinforcement may confer certain methodological advantages. First, rodents experience and discriminate objects using active exploratory behaviors including whisking and sniffing (Diamond et al. 2008; Sullivan et al. 2012) and find interaction with objects rewarding (Peartree et al. 2012). Vigorous exploration of objects is commonly observed in the novel object recognition (NOR) test, where performance is measured by the duration of investigation toward the more salient, novel object (Antunes and Biala 2012). Guterl et al. (2015) measured conditioned object preferences based on time spent in the compartment containing the respective objects, a similar measure as that used for CPP. As such, it remains unclear whether an animal's interaction with drug-paired objects is amenable to measurement during each phase of stimulus exposure (i.e., during conditioning as well as testing), allowing for a detailed analysis of acquisition and expression of conditioned approach. Second, behavioral tests wherein rodents are given simultaneous access to three or more objects are relatively common (Frick and Gresack 2003; Palchykova et al. 2006; Oliveira et al. 2010). Thus, object cues may allow for the assessment of conditioned responses to three or more stimuli, for example, to generate a dose-effect curve, which can be timeconsuming when using CPP (Bardo and Bevins 2000). Finally, use of objects as conditioned cues allows for the analysis of an additional, and critical, dimension of conditioned reinforcement learning; namely, the context in which conditioning occurs. As well as directly eliciting conditioned responses, contextual cues can act as "occasion-setters" for responses to explicit cues (Bouton and Swartzentruber 1986). For example, a switch in context may produce "renewal" of conditioned responding following extinction (Thewissen et al. 2006). Hence, the presence of objects as conditioned stimuli may allow for further investigation of modulatory influences of contexts on conditioned behavior.

In a series of experiments (Fig. 1), we sought to explore the utility of objects as drug-conditioned stimuli in rats by pairing different objects with cocaine. We first determined whether rats would exhibit an enduring preference for an object previously experienced following cocaine injection. Next we examined extinction and drug-primed reinstatement of a preference for a cocaine-paired object. This experiment also enabled us to assess whether the strength of a conditioned object preference (COP) was predicted by the animal's engagement with the drug-paired object during conditioning. A third experiment tested the use of three objects simultaneously to assess preference for stimuli paired with different cocaine doses. Finally, we assessed the Pavlovian phenomenon of renewal by extinguishing the rats' preference for the cocaine-paired object in a second environment and then retesting for COP in the original test chamber. Taken as a whole, these experiments provide strong support for the future incorporation of object cues in tests of appetitive Pavlovian conditioning in rats.

\section{Results}

\section{Experiment 1}

Experiment 1 (Fig. 1) was an initial test to determine whether rats would preferentially investigate an object paired with cocaine and whether the strength of this preference would vary as a function of the degree of training. To address this question, animals were conditioned for $2 \mathrm{~d}$ and received one saline and one cocaine $(20 \mathrm{mg} /$ $\mathrm{kg}$ ) conditioning session prior to post-test 1 . Following post-test 1 , rats received two additional days of conditioning with one saline and one cocaine session. A second post-test (post-test 2) was conducted $24 \mathrm{~h}$ after the final conditioning day.
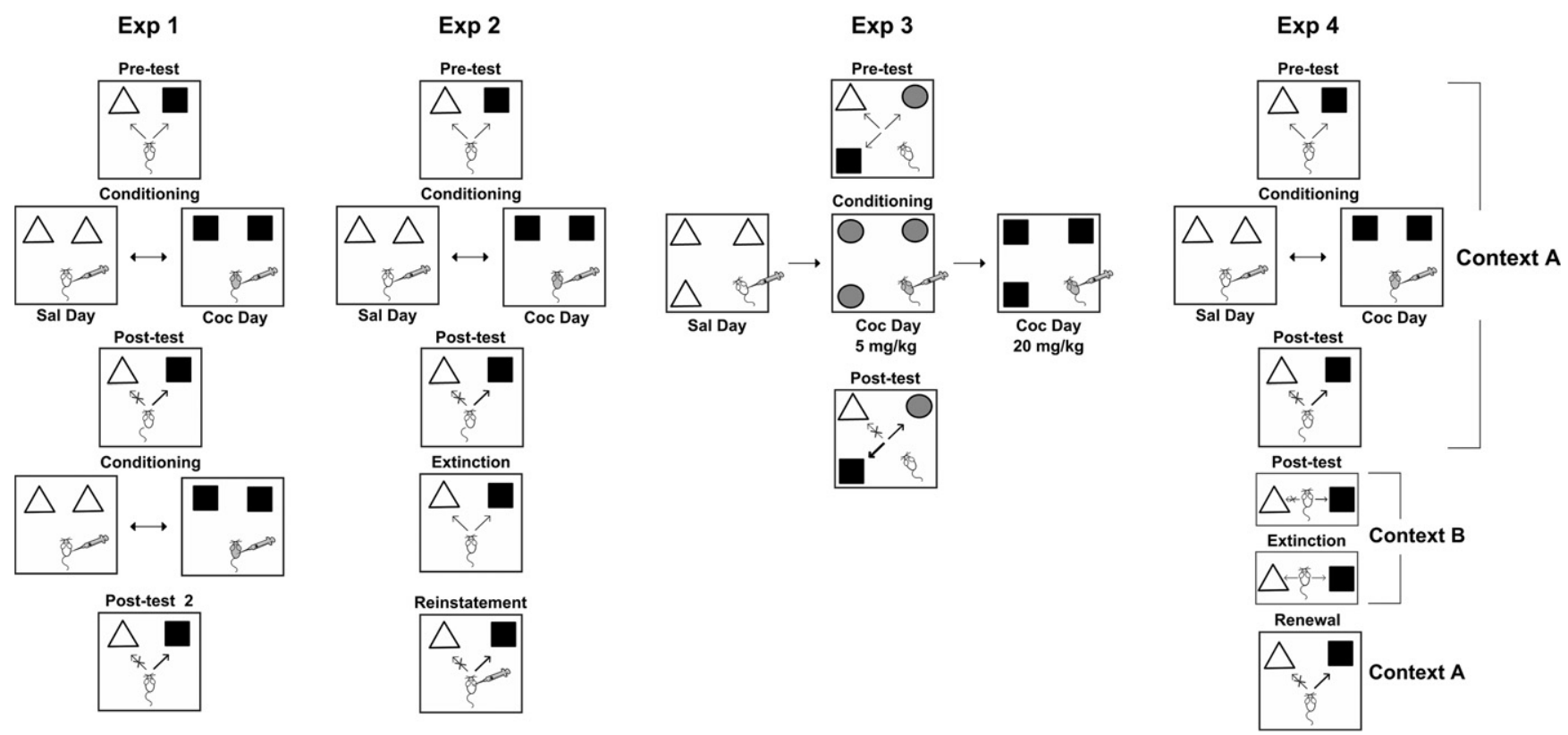

Figure 1. Schematic depicting overview for conditioned object preference testing in each experiment. 

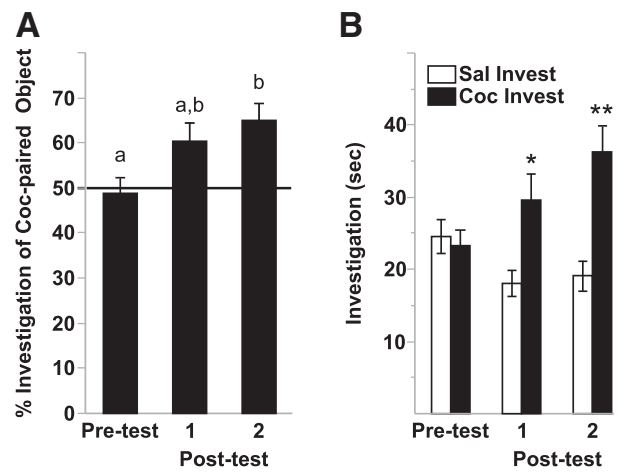

Figure 2. Preference for cocaine-paired object following one or two conditioning sessions. $(A)$ Percent of total investigation time spent exploring the cocaine-paired object during the pretest and following one (posttest 1) or two (post-test 2) rounds of conditioning. Bars without a common letter differ, $P<0.05$. (B) Total duration of investigation toward the saline- and cocaine-paired objects at each test phase. $\left(^{*}\right)$ $P<0.05,\left(*^{*}\right) P<0.001$, versus saline-paired object within the same test. $N=14$, graphs depict mean \pm SEM.

Object preference differed based on the amount of conditioning $\left(F_{(2,39)}=5.74, P=0.009 ; \alpha=0.05\right)$ with increased preference for the cocaine-paired object in the post-tests compared with the pretest (Fig. 2A). Tukey's HSD post hoc tests revealed that this effect was not significant for post-test $1(P=0.062)$, but a significant increase in preference was found for post-test $2(P=0.008)$. Although preference scores at post-test 1 did not differ from the pretest, they also did not differ from post-test 2 $(P=0.624)$, indicating intermediate preference scores at post-test 1 and thereby supporting the prediction of a stronger preference for the cocaine-paired object following an additional round of conditioning.

Rats explored the cocaine-paired objects for longer than saline-paired objects (Fig. 2B, effect of object pairing, $F_{(1,82)}=$ $11.368, P=0.005)$, and this effect varied according to the amount of conditioning (object pairing $\times$ conditioning interaction, $\left.F_{(2,81)}=5.835, P=0.0075\right)$. Tukey's HSD post hoc tests showed that investigation of the saline-paired object was consistent across testing (vs. pretest: post-test $1, P=0.39$; post-test $2, P=0.60$ ), whereas investigation of the cocaine-paired object was unchanged at post-test $1(P=0.34)$ but increased significantly by post-test $2(P=0.002)$. Consistent with preference scores, no difference was found between investigation of the cocaine-paired object between post-test 1 and $2(P=0.28)$. Additional analysis using planned contrasts between time spent exploring the saline versus cocaine-paired object revealed that rats spent approximately equal time exploring the cocaine- and saline-paired objects during the pretest $\left(F_{(1,82)}=0.04, P=0.83\right)$ but investigated the cocainepaired object significantly more during post-test $1\left(F_{(1,82)}=7.86\right.$, $P=0.008)$ and post-test $2\left(F_{(1,82)}=17.43, P<0.0002\right)$. Finally, investigation of the cocaine-paired object, but not the saline-paired object, exhibited a linear relationship with the amount of conditioning (cocaine: $\mathrm{rsq}=0.15, P=0.01$; saline: $\mathrm{rsq}=0.06, P=$ 0.098), indicating increased investigation of the cocaine-paired objects with additional conditioning.

\section{Experiment 2}

Experiment 2 (Fig. 1) was conducted to assess whether conditioned object preferences show extinction and reinstatement and to further validate the results of experiment 1 using a saline-only control group (experiment 2A). Cocaine-treated animals received $6 \mathrm{~d}$ of conditioning alternating daily between saline and cocaine $(20 \mathrm{mg} / \mathrm{kg})$. Conditioning was identical in saline-only groups but animals received daily saline injections (i.p.) of equivalent volume. After conditioning, animals received a single post-test followed by extinction and cocaine-primed reinstatement $(10 \mathrm{mg} / \mathrm{kg}$, i.p.). A second aim of experiment 2 was to evaluate the relationship between object investigation during conditioning and preference for the cocaine-paired object in the post-test (experiment 2B).

\section{Experiment 2A}

Consistent with the results of experiment 1 , object preference in experiment $2 \mathrm{~A}$ varied across testing (Fig. $3 \mathrm{~A}, F_{(4,87)}=2.58, P=$ 0.046). Preference scores also differed between cocaine-treated and saline-only animals (saline only in Supplemental Figure 1A, effect of treatment, $F_{(1,90)}=5.18, P=0.037$ ) with higher overall preference for the cocaine-paired object in cocaine-treated animals. This effect appeared to be dependent on testing phase, although the interaction failed to reach significance (test $\times$ treatment interaction, $F_{(4,87)}=2.25, P=0.073$ ). Post hoc comparisons (Bonferroni-corrected significance set at $P<0.0125$ ) between post-tests and pretest preference scores within each treatment group revealed different patterns of object preference scores across testing. Cocaine-treated $(P=0.008)$ but not saline-only $(P=0.82)$ animals exhibited significantly higher preferences for
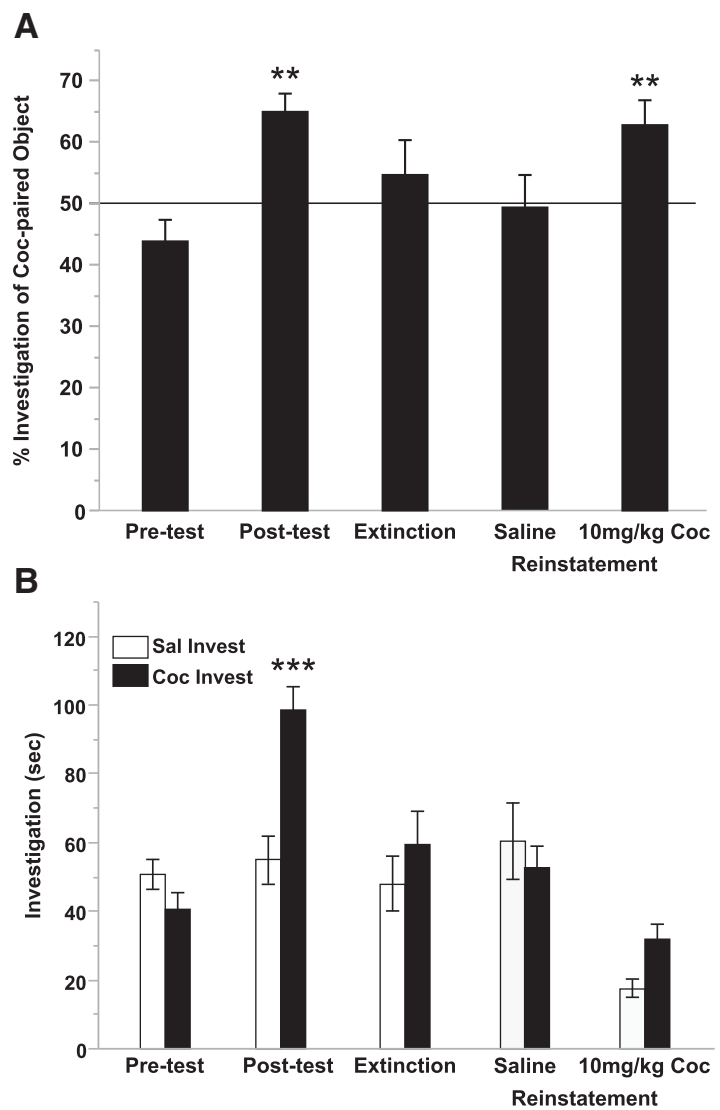

Figure 3. Extinction and cocaine-primed reinstatement of cocainepaired object preference. $(A)$ Percent of total investigation time spent investigating the cocaine-paired object. Percentage scores shown at the pretest, following conditioning (post-test) and extinction, and for saline- or cocaine-primed reinstatement. $\left(^{* *}\right) P<0.01$ versus pretest percentage. $(B)$ Duration of investigation toward the saline- and cocainepaired objects across each test phase. $\left.{ }^{* * *}\right) P<0.001$ versus saline-paired object within the same test. $N=12$, graphs depict mean \pm SEM. 
the cocaine-paired object at post-test 1 versus pretest values. Following extinction, preference scores of both groups returned to pretest values (cocaine treated, $P=0.09$; saline only, $P=$ 0.46). During reinstatement testing, saline injections alone failed to alter object preferences in either treatment group (vs. pretest: cocaine treated, $P=0.35$; saline only, $P=0.14$ ). However, the cocaine prime $(10 \mathrm{mg} / \mathrm{kg})$ delivered before testing increased preference for the cocaine-paired object in cocaine-treated rats (vs. pretest: $P=0.0034)$ but not saline-only rats $(P=0.68)$.

Cocaine-treated animals exhibited a greater investigation bias toward the cocaine-paired object relative to saline-only animals (saline-only data in Supplemental Fig. 1B, object pairing $x$ treatment interaction, $\left.F_{(4,177)}=2.561, P=0.046\right)$. This effect was also confirmed by planned contrasts between saline- and cocaine-paired object investigation times for both treatment groups at each test phase. Investigation of the cocaine- versus saline-paired objects was similar during the pretest in both treatment groups (Fig. 3B, cocaine treated, $F_{(1,180)}=0.92, P=0.34$; saline only, $\left.F_{(1,180)}=0.0006, P=0.98\right)$. Following conditioning, cocaine-treated $\left(F_{(1,180)}=15.35, P=0.0002\right)$ but not saline-only rats $\left(F_{(1,180)}=0.35, P=0.55\right)$ investigated the cocaine-paired object significantly more than the control object. All animals investigated both objects equally following extinction (cocaine treated, $F_{(1,180)}=0.89, P=0.34$; saline only, $\left.F_{(1,180)}=0.06, P=0.79\right)$ and following a saline prime during reinstatement testing (cocaine treated, $F_{(1,180)}=0.34, P=0.56$; saline only, $F_{(1,180)}=2.42, P=$ $0.12)$. Finally, no difference in investigation was found between the cocaine- and saline-paired objects following a cocaine prime in either group (cocaine treated, $F_{(1,180)}=1.27, P=0.26$; saline only, $\left.F_{(1,180)}=0.104, P=0.75\right)$, despite the reinstatement of preference for the cocaine-paired object observed in cocaine-treated animals (Fig. 3A).

\section{Experiment 2B}

Investigation of objects by cocaine-treated animals during conditioning was significantly lower for cocaine versus saline sessions (Fig. 4A, $\left.F_{(1,70)}=8.11, P=0.016\right)$. Object investigation trended toward a decrease across conditioning days $\left(F_{(2,69)}=2.94, P=\right.$ 0.073 ) but only for cocaine conditioning sessions (conditioning day $\times$ drug interaction, $\left.F_{(2,69)}=5.05, P=0.016\right)$. While the dura- tion of object investigation during cocaine conditioning was similar to saline sessions on day 1 (Tukey's HSD, $P=0.99$ ), object investigation on cocaine days 2 and 3 was significantly lower than both cocaine day 1 (vs. day $2, P=0.041$; vs. day $3, P=$ $0.01)$ and the respective saline day on day $3(P=0.02)$ with this comparison approaching significance on day $2(P=0.079)$. Comparisons of object investigation during cocaine conditioning sessions with preference for the cocaine-paired object in post-test 1 revealed a strong linear relationship that was dependent on the conditioning day. Whereas object investigation during cocaine conditioning days 2 (Fig. $4 \mathrm{~B}, R=0.728, P=0.011)$ and $3(R=$ $0.746, P=0.008$ ) was positively correlated with preference for the cocaine-paired object at post-test 1 , this was not true on cocaine day $1(R=0.49, P=0.12)$. Likewise, object investigation during saline conditioning was not correlated with preference for the cocaine-paired object on conditioning days 1-2 (saline day $1, R=0.083, P=0.79$; day $2, R=0.158, P=0.64$ ) and exhibited a trend toward a negative relationship on day $3(R=-0.597$, $P=0.052)$.

\section{Experiment 3}

Experiment 3 (Fig. 1) was designed to test whether three objects could be used simultaneously within the COP test. This experiment compared preferences for three different objects, two paired with different doses of cocaine ( 5 and $20 \mathrm{mg} / \mathrm{kg}$ ) and one paired with saline. Animals were tested using three different test objects placed in three of the four corners of the test chamber with consistent object locations across pre- and post-tests.

Generally, preference for cocaine-paired objects was higher in the post- versus pretest (combined 5 and $20 \mathrm{mg} / \mathrm{kg}, F_{(1,32)}=$ $10.6, P=0.0047)$. As expected, this effect was dependent on cocaine dose. Whereas preference for the $20 \mathrm{mg} / \mathrm{kg}$ cocaine-paired object increased during the post-test (Fig. 5A, versus pretest, $\left.F_{(1,32)}=5.36, P=0.034\right)$, preference for the $5 \mathrm{mg} / \mathrm{kg}$ dose remained unchanged across testing $\left(F_{(1,32)}=0.122, P=0.73\right)$. Thus, while preference for each object was equivalent in the pretest (20 mg/kg: 32.75\%, $5 \mathrm{mg} / \mathrm{kg}: 34.79 \%$, saline: $32.45 \%$ ), object preference in the post-test was highest for the $20 \mathrm{mg} / \mathrm{kg}$ cocaine dose (44.13\%), followed by the $5 \mathrm{mg} / \mathrm{kg}$ dose (33.43\%), and lowest for the saline-paired object (22.34\%).
A

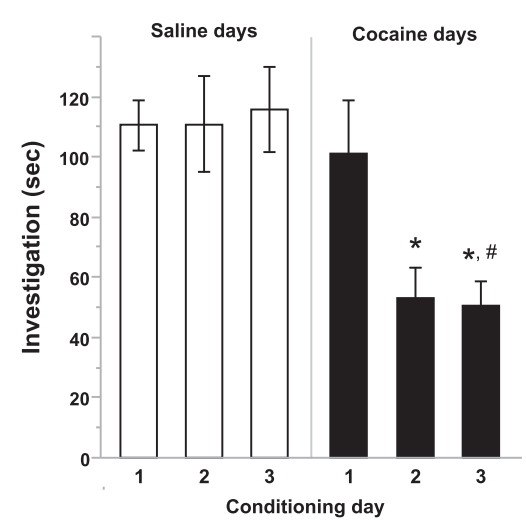

B
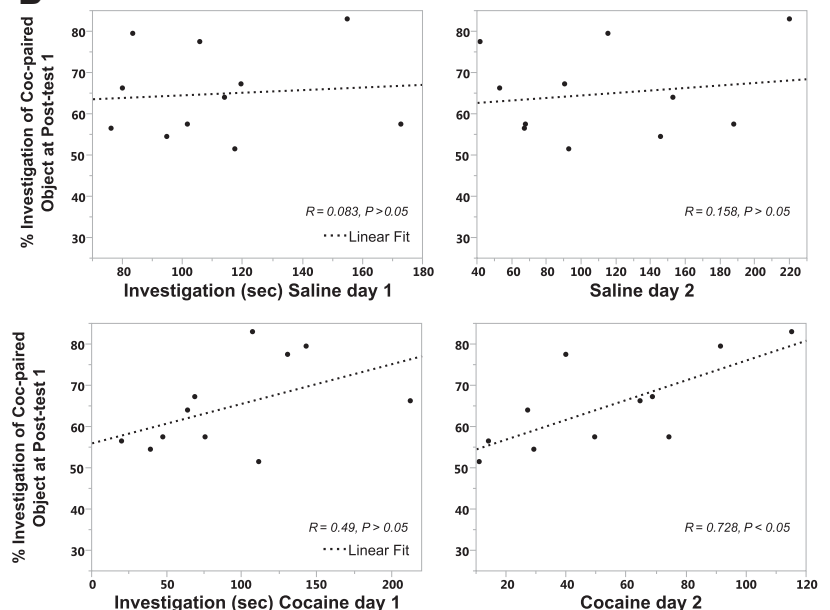

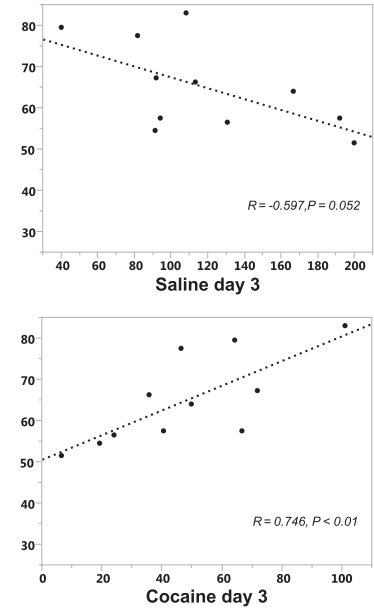

Figure 4. Object exploration during saline and cocaine conditioning in cocaine-treated animals. $(A)$ Total duration time spent investigating objects during each of the three saline and cocaine conditioning days. (*) $P<0.05$ versus cocaine conditioning day 1 , (\#) $P<0.01$ versus saline conditioning day 3. (B) Linear regressions between total duration of object investigation during each saline (top) and cocaine (bottom) conditioning day and cocainepaired object preference during the subsequent post-test. Dotted lines indicate best linear fit. $N=12, \mathrm{graphs}$ depict mean \pm SEM. 

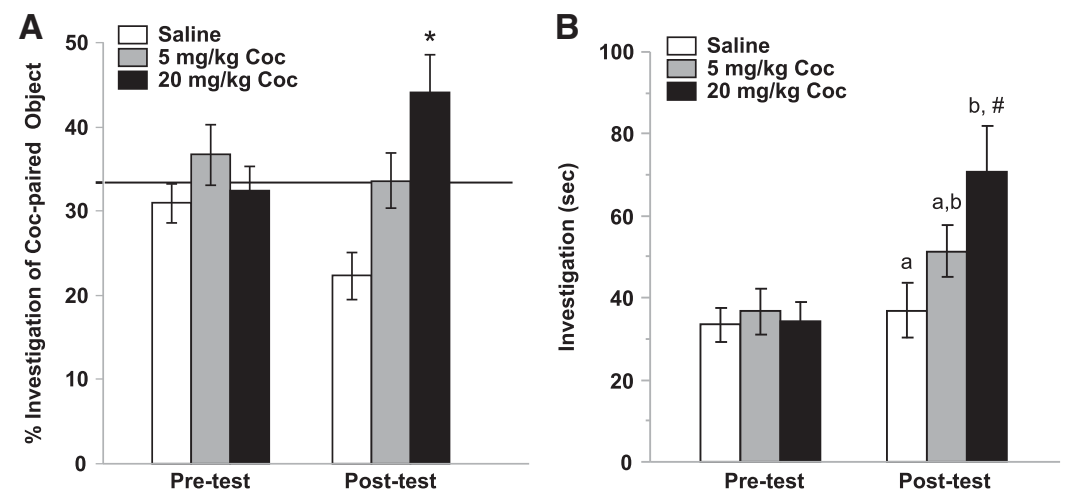

Figure 5. Preference for cocaine-paired objects in three-object preference test. $(A)$ Percent of total investigation spent exploring the objects paired with 5 and $20 \mathrm{mg} / \mathrm{kg}$ cocaine. $\left({ }^{*}\right) P<0.05$ versus pretest percentage for that dose. (B) Duration of investigation toward saline, $5 \mathrm{mg} / \mathrm{kg}$, and $20 \mathrm{mg} / \mathrm{kg}$ cocainepaired objects. Post-test durations without a common letter differ. $P<0.05$, (\#) $P<0.001$ versus pretest duration for that object. $N=18$, graphs depict mean \pm SEM

Object investigations times were dependent on drug-dose $\left(F_{(2,97)}=4.77, P=0.015\right)$, but this effect was only observed in the post-test (dose $\times$ test interaction, $F_{(2,97)}=5.28, P=0.01$ ). In the post-test, object investigation followed a similar pattern as object preference with highest-to-lowest investigation durations: 20 $\mathrm{mg} / \mathrm{kg}(70.78 \mathrm{sec}), 5 \mathrm{mg} / \mathrm{kg}(51.31 \mathrm{sec})$, and saline $(36.75 \mathrm{sec})$. Post-test investigation of the $20 \mathrm{mg} / \mathrm{kg}$ cocaine-paired object was significantly higher relative to both investigation of the same object during the pretest (Fig. 5B, Tukeys HSD, $P<0.0001$ ) and the saline-paired object at the post-test $(P=0.001)$. The 5 $\mathrm{mg} / \mathrm{kg}$ cocaine-paired object was explored at an intermediate level that was not different from exploration levels of either the saline $(P=0.48)$ or $20 \mathrm{mg} / \mathrm{kg}$ cocaine-paired objects $(P=0.157)$. Regression analysis of object investigation across increasing cocaine doses revealed a significant linear relationship during the post-test (rsq $=0.16, P=0.006$ ) but not the pretest (rsq= $0.0003, P=0.90)$. No differences in object investigation were observed in the pretest (Ps $>0.99$ ).

\section{Experiment 4}

A final experiment (Fig. 1) was conducted to examine whether context can alter preference for a cocaine-paired object. Rats were tested for cocaine COP in the classic A-B-A design used to assess renewal of drug-seeking behavior (Bouton 1988; Thewiseen et al. 2006). Animals were first given a pretest, conditioning, and posttest identical to those described in experiment 2 . These tests were conducted in the same chamber used in experiments 1-3 (environment A). Animals were then extinguished within a new chamber (environment B), prior to a final post-test in environment A.

Preference for the cocaine-paired object did not differ across test phases (Fig. $\left.6 \mathrm{~A}, F_{(4,56)}=1.52, P=0.21\right)$. However, object investigation times were affected by object pairing $\left(F_{(1,119)}=10.20\right.$, $P=0.008)$, and this effect varied by test phase (Fig. 6B, object pairing $\times$ test phase interaction, $F_{(4,116)}=2.92, P=$ 0.032). Planned contrasts between saline- and cocaine-paired object investigation times at each test revealed equivalent levels of exploration in the pretest $\left(F_{(1,119)}=\right.$ $0.009, P=0.92$ ) but increased investigation for the cocaine-paired object in the post-test in environment A $\left(F_{(1,119)}=13.36, P<\right.$ $0.0006)$. Significantly higher exploration of the cocaine-paired object was also observed in environment $\mathrm{B}\left(F_{(1,119)}=7.19, P=\right.$ $0.009)$, but this effect was lost following extinction $\left(F_{(1,119)}=\right.$ $0.018, P=0.89$ ). Finally, investigation for the cocaine-paired object was again higher when animals were retested in environment A $\left(F_{(1,119)}=5.19, P=0.027\right)$.

\section{Discussion}

These experiments demonstrated that rats exhibit a preference for an object or objects that have been paired with cocaine exposure. The animals' preferences were similar in magnitude to those commonly reported toward an environment paired with the same dose of cocaine (Adams et al. 2001; Botreau et al. 2006; Brenhouse and Andersen 2008). Not only were object preferences robust, but they could be acquired to a variety of different objects. This behavioral measure was also sensitive to the dose of cocaine, with preferences for three different objects varying as a function of the cocaine dose associated with each. Finally, the use of objects as
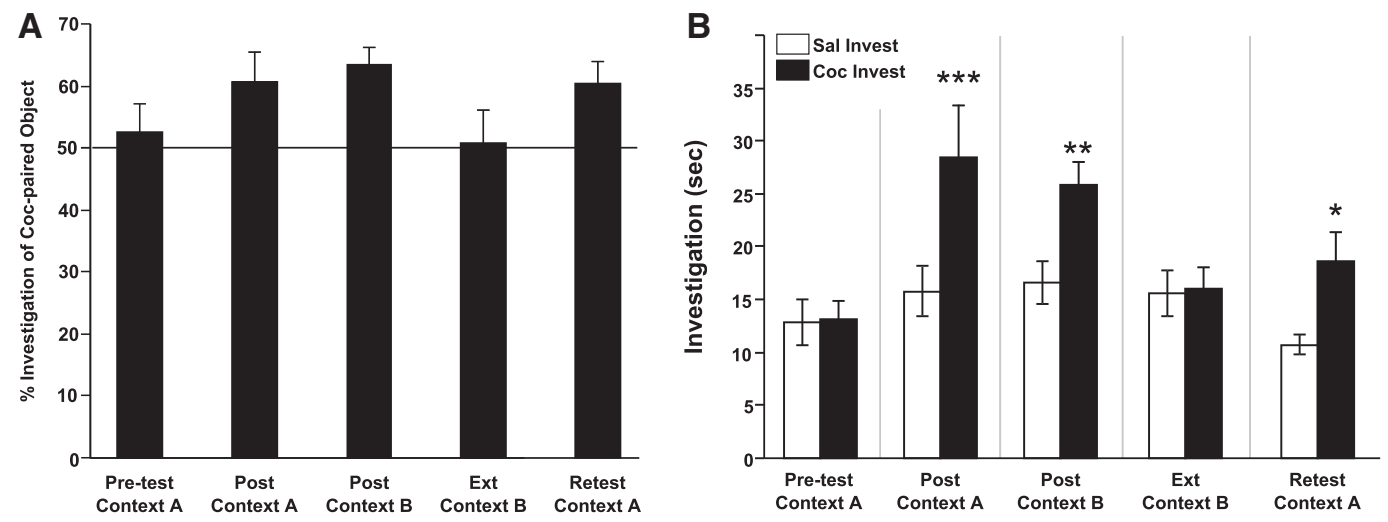

Figure 6. Renewal of cocaine conditioned object preference. Rats received pre- and post-tests in one environment $(A)$, and a further post-test in a second, novel environment $(B)$. Following extinction within environment $B$, animals were returned to environment $A$ for a final post-test (retest). Cocaine-paired object preferences were assessed using $(A)$ percentage of total investigation spent investigating the cocaine-paired object at each test phase and $(B)$ duration of investigation toward saline- and cocaine-paired objects. $\left(^{*}\right) P<0.05,\left({ }^{*}\right) P<0.01,\left({ }^{* *}\right) P<0.001$ versus saline-paired object within the same test. $N=12$, graphs depict mean \pm SEM. 
conditioned stimuli proved amenable to the demonstration of the Pavlovian phenomena of extinction, reinstatement, and renewal. Taken together, these findings point to the potential utility of $\mathrm{COP}$ as an alternative paradigm for assessing reward-related learning and behavior.

The strength of the association between cues after Pavlovian learning is largely determined by the degree of training (i.e., number of stimulus pairings) and the magnitude of reward (Rescorla and Wagner 1972). In the current experiments, we found that the strength of the cocaine-paired object preference varied predictably as a function of both these parameters. Rats exhibited a stronger cocaine preference following two conditioning periods versus one and their preferences were more pronounced when higher $(20 \mathrm{mg} / \mathrm{kg}$ ) versus lower $(5 \mathrm{mg} / \mathrm{kg})$ doses of cocaine were given. Hence, within the parameters of the current study, COP faithfully reflected the strength of the underlying Pavlovian association between the conditioned object and the signal for reward.

It is important to note that despite evidence of clear preferences for one object over another, the amount of time allocated to engagement with the objects as a whole still made up a relatively small proportion of the total time spent in the test environment. This feature of COP has at least three implications for the application of this paradigm in future experimental studies. First, it rules out the possibility that preference for a cocainepaired object simply reflects an aversion to the alternate choice (i.e., the saline-paired object). Animals are free to avoid both objects, and thus preference behavior does not reflect a forced choice between the two object cues. This alternative explanation cannot be discounted as easily when it comes to place preference, except in designs that include a third (middle) compartment. The short duration of object exploration relative to the totality of behaviors exhibited also means that the rat's interaction with the objects during the training sessions themselves becomes a potentially valuable source of data. An indication that this measure is meaningful is the fact that the animals' engagement with the cocainepaired objects over the course of training correlated significantly with the degree of object preference exhibited in the post-test. Again, such an online readout of motivated behavior during training is not available to the experimenter conducting a CPP experiment, in which an animal is necessarily confined to the to-be-paired environment for the entirety of each training session.

A third implication of the small proportion of time rats spend in proximity to the object cues is that object-specific approach behavior can be disambiguated from nonspecific effects, such as reduced or increased locomotor behavior (that would result from sedation or psychomotor sensitization respectively), or increases in competing behaviors (e.g., exploration, rearing, and grooming). Nonspecific behavioral effects may reduce overall object exploration but not the relative preference for one object over another. For example, although a $10 \mathrm{mg} / \mathrm{kg}$ priming injection of cocaine drastically reduced overall levels of object investigation in the test for reinstatement, we were still able to detect a discernable reinstatement of the rats' preference for the cocaine-paired object. These results highlight a potential limitation of the COP test. Treatments or conditions that interfere with object investigation may make it difficult to assess accurate object preferences due to a floor effect. Extremely low investigation values may exaggerate both high and low preferences, leading to greater variability. However, it is precisely the ability of the COP measure to distinguish raw investigation from relative preference that allows for detection of such issues. Overall, object-directed conditioned approach behavior offers a striking degree of behavioral specificity.

A further valuable feature of an object preference task is that learning and retrieval occur within a context that can be system- atically manipulated. Expression of object preferences should therefore be subject to "occasion-setting" by contextual cues, as has been demonstrated in many other Pavlovian paradigms (Bouton and Swartzentruber 1986; Bouton 1988). In the present study, we determined whether animals exhibited "renewal" of a preference for a cocaine-paired object. Renewal was assessed by returning animals to the environment in which cocaine was first experienced following extinction within an alternative environment. A preference for the cocaine-paired object, which diminished to pretest values over the course of extinction in a new context, reemerged when the rats were placed back in the conditioning context. This suggests that context can serve as an occasion-setter for the expression of object preferences, making COP a useful paradigm for studying the modulatory role of context in functional and dysfunctional reward-related learning and behavior.

Although rats exhibited clear preferences for cocaine-paired objects, the motivation driving this behavior is less clear. It is well established that animals reliably exhibit consummatory-like behaviors, referred to as sign tracking or autoshaping, toward cues paired with rewards (Brown and Jenkins 1968), even if this behavior results in withholding of the reward (Williams and Williams 1969). This nonteleological form of behavior contrasts with goal tracking, or behavior directed toward the source of the reward, such as a food hopper (Farwell and Ayres 1979). A body of recent work suggests that rats can be categorized according to whether they predominantly acquire sign- or goal-tracking behavior. "Sign trackers" are more likely to acquire addiction-like behavior (Flagel et al. 2008), and cues to which sign-tracking behavior is directed (e.g., the response lever in an operant chamber) are more likely to acquire incentive salience, i.e., the ability to serve as reinforcers themselves (for review, see Flagel et al. 2009). For this reason, the study of sign versus goal tracking can inform our understanding of mechanisms underlying individual differences in vulnerability to addictive behavior (Flagel et al. 2010). If we accept that the animals' interaction with the objects in our experiments reflected sign-tracking behavior, it is interesting to note that this behavioral pattern was exhibited to some degree by almost all rats. A critical difference between COP and conditioning for food in an operant box is that in the former the opportunity to engage in goal-directed behavior is absent. This may suggest that rats are not destined to act solely as sign- or goal-trackers, but rather to exhibit sign-tracking behavior if there is no proximal source of the reward to which they can direct their responses.

Overall, these findings support COP as a valuable assay of drug-seeking behaviors in rodents capable of providing similar measures of acquisition, extinction, and reinstatement of cocaine preference as CPP. Despite minor discrepancies in level of significance, we found good agreement between object preference and raw investigation scores and both measures supported a robust preference for the cocaine-paired object across multiple tests. Furthermore, conditioned object preference provides opportunities to explore novel questions. As demonstrated in the present study, this task allows for the establishment of dose-response relationships by using multiple object cues and is also well suited for investigation of the effects of environment on conditioned preference. However, the COP is not without limitations. For example, object investigation is not as amenable to automated analysis as the locomotor behavior used to assess CPP. Furthermore, as addressed above, COP may be particularly sensitive to floor effects on object exploration. Given the particular strengths of the COP and CPP tests, these behavioral assays are ideally suited as complementary measures of reward-seeking behavior. Overall, given an inherently straightforward methodology that uses readily available materials, and the flexibility offered in terms of experimental design, COP promises to become a customizable test for 
investigating mechanisms of reward processing and associated psychopathologies.

\section{Materials and Methods}

\section{Subjects}

Charles River-derived Sprague-Dawley rats (Charles River, Wilmington, VA) were housed in a vivarium on a 12-h lightdark cycle where they were provided with ad libitum food and water. All behavioral tests were conducted during the light phase. Behavioral testing was conducted in adult male rats at P65 or older. All experiments were approved by the University of Minnesota Institutional Animal Care and Use Committee.

\section{Conditioned object preference}

The conditioned object preference procedure was modified from an NOR task used previously (Kennedy et al. 2014). Prior to the start of testing, rats were handled for $2 \mathrm{~d}$ followed by $2 \mathrm{~d}$ of habituation to the test chamber for $10 \mathrm{~min} / \mathrm{d}$ (black ABS plastic, 50 $\mathrm{cm} \times 50 \mathrm{~cm} \times 50 \mathrm{~cm})$. The basic test procedure used for all experiments consisted of a pretest, conditioning, and a post-test (Fig. 1), although test durations and length of conditioning varied by experiment (see experiment-specific sections below). During the pretest, rats were placed in the test chamber containing either two or three different test objects secured to the floor using fasteners. Following the pretest, conditioning was conducted by injecting animals with either saline $(0.9 \%)$ vehicle or cocaine $\mathrm{HCl}(5$ or $20 \mathrm{mg} / \mathrm{kg}$, Research Triangle Institute) and placing them into the test chamber for $25 \mathrm{~min}$ with two (experiments 1, 2, 4) or three copies (experiment 3 ) of the same object. Treatment alternated daily between saline and cocaine, and a different object was paired with each treatment. Injections were always delivered intraperitoneally (i.p.) in a $1 \mathrm{~mL} / \mathrm{kg}$ volume. Post-tests were identical to the pretest and were conducted in drug-free animals $24 \mathrm{~h}$ following the final conditioning day. Both pre- and post-tests, as well as some conditioning sessions (experiment $2 \mathrm{~B}$ ), were video recorded by a camera positioned directly above the test chamber. All videos were scored for the duration of object investigation (nose $<2 \mathrm{~cm}$ from object) by a trained rater blind to group assignment using computer-assisted software (Button box; Behavioral Research Solutions). Conditioned object preference was analyzed using either the percentage of total investigation directed toward the cocaine-paired object or a comparison of raw investigation duration directed toward the cocaine versus saline objects. A subset of videos was scored by a second rater to validate object preference scores. Correlations between independent scoring of object preferences were strong $(R s=0.871-0.955)$.

Chambers were wiped down with $70 \%$ ethanol and objects were cleaned with bleach water between testing. Multiple object pairs were used for each experiment but test object pair, as well as conditioning order and drug-paired object location during testing were all counterbalanced across animals. Objects were of similar size but varied in color, material, texture, or shape and included small plastic or rubber dog toys as well as plastic cups and bowls. Across all experiments, each object within a test pair was investigated equally during the pretest, indicating that no objects were inherently preferred or avoided by the rats (Ps $>0.05$, data not shown).

\section{Experiment 1}

Rats were conditioned for $2 \mathrm{~d}$ and received one saline and one cocaine $(20 \mathrm{mg} / \mathrm{kg})$ conditioning session prior to the post-test 1. Following post-test 1 , rats received two additional days of conditioning with one saline and one cocaine session. A second posttest (post-test 2) was conducted $24 \mathrm{~h}$ after the final conditioning day. Pre- and post-tests were $5 \mathrm{~min}$ in length.

\section{Experiment $2 \mathrm{~A}$}

Cocaine-treated animals received $6 \mathrm{~d}$ of conditioning alternating daily between saline and cocaine $(20 \mathrm{mg} / \mathrm{kg})$. Conditioning was identical in saline-only groups, but animals received daily saline injections (i.p.). After conditioning, animals received a single post-test followed by extinction and cocaine-primed reinstatement. Extinction was performed with daily, $10 \mathrm{~min}$ tests over $6 \mathrm{~d}$ in which both objects were presented without additional cocaine or saline administration. Cocaine-primed reinstatement was assessed $24 \mathrm{~h}$ after the final extinction day in 10-min object preference tests conducted over $2 \mathrm{~d}$. On the first day, animals were retested for object preference following a saline injection (i.p.). On the second day, all animals, including saline-only groups, received a cocaine prime $(10 \mathrm{mg} / \mathrm{kg}$, i.p.) immediately prior to testing. All tests including pre- and post-tests were 10 min in length.

\section{Experiment $2 \mathrm{~B}$}

Saline and cocaine conditioning sessions for the animals used in Experiment 2A were video recorded and rated for object investigation. Object investigation during saline or cocaine conditioning for each animal was compared with subsequent preference for the cocaine-paired object in the post-test using a linear regression.

\section{Experiment 3}

Three different objects were used for testing and conditioning. Test objects were placed in three of the four corners of the test chamber with consistent object locations across pre- and posttests. Animals received $9 \mathrm{~d}$ of conditioning which alternated daily between saline, $5 \mathrm{mg} / \mathrm{kg}$, and $20 \mathrm{mg} / \mathrm{kg}$ cocaine, with a different object paired with each treatment. Treatments were always given in this order but the treatment received on the first conditioning day was counterbalanced across animals. During conditioning, three identical copies of the designated object were placed in the test chamber. Pre- and post-tests were $10 \mathrm{~min}$ in length.

\section{Experiment 4}

Rats received a pretest, conditioning, and post-test, identical to those described in experiment 2 . These tests were conducted in the same chamber used in experiments 1-3 (environment A). Animals were then given a second COP post-test in a new chamber (environment B). Environment B was a chamber with the same size as the home cage with opaque plastic walls. Rats were tested in these chambers without bedding and objects were secured on the cage floor at opposite sides of the chamber. Environments A and B were thoroughly cleaned with $70 \%$ ethanol between tests. After the post-test in environment $B$, rats received additional tests without cocaine or saline administration to facilitate extinction similar to the extinction performed in experiment $2 \mathrm{~A}$. After preference for the cocaine-paired object had returned to baseline values following extinction, rats were given a final post-test in the original environment A. All tests in both environments were 5 min in length.

\section{Statistical analysis}

Analysis of object preferences, such as in the NOR task, can be performed using multiple different approaches (Antunes and Biala 2012). To assess conditioned object preference, the present study adapted two commonly used measures, percent of total investigation time spent with the cocaine-paired object and raw investigation time directed toward the cocaine- and saline-paired objects. Percent preference for the cocaine-paired object and duration of investigation toward each object were compared between groups and across test phases using mixed-effects analysis of variance (ANOVA) to assess within- and between-subjects effects. Significant effects were further explored using Tukey's HSD to determine significant comparisons. Due to the large number of comparisons possible with the addition of a saline-only control group in experiment $2 \mathrm{~A}$, Bonferroni-corrected post hoc tests were used instead to explore the change in object preferences across testing within each treatment group (Bird 1975). Planned contrasts were used to compare investigation times between cocaineand saline-paired objects at each test phase in experiments 2 and 
4. Linear regressions were assessed using Pearson's correlation coefficient. Uncorrected significance levels $(\alpha)$ were set at $P<0.05$.

\section{Acknowledgments}

The authors would like to acknowledge Michael Benneyworth and Jack Smethells for their valuable feedback on the design of the COP experiments. This work was supported by a Grant-inAid of Research Award from the University of Minnesota to J.C.G.

\section{References}

Adams JU, Careri JM, Efferen TR, Rotrosen J. 2001. Differential effects of dopamine antagonists on locomotor activity, conditioned activity and conditioned place preference induced by cocaine in rats. Behav Pharmacol 12: 603-611.

Antunes M, Biala G. 2012. The novel object recognition memory: Neurobiology, test procedure, and its modifications. Cogn Process 13: 93-110.

Bardo MT, Bevins RA. 2000. Conditioned place preference: What does it add to our preclinical understanding of drug reward? Psychopharmacology (Berl) 153: 31-43.

Bassareo V, Di Chiara G. 1997. Differential influence of associative and nonassociative learning mechanisms on the responsiveness of prefrontal and accumbal dopamine transmission to food stimuli in rats fed ad libitum. J Neurosci 17: 851-861.

Beach HD. 1957. Morphine addiction in rats. Can J Psychol 11: 104-112.

Bird KD. 1975. Simultaneous contrast testing procedures for multivariate experiments. Multivariate Behav Res 10: $343-351$.

Botreau F, Paolone G, Stewart J. 2006. D-Cycloserine facilitates extinction of a cocaine-induced conditioned place preference. Behav Brain Res 172: $173-178$.

Bouton ME. 1988. Context and ambiguity in the extinction of emotional learning: Implications for exposure therapy. Behav Res Ther 26: $137-149$.

Bouton ME, Swartzentruber D. 1986. Analysis of the associative and occasion-setting properties of contexts participating in a Pavlovian discrimination. J Exp Psychol Anim Behav Process 12: 333-350.

Brenhouse HC, Andersen SL. 2008. Delayed extinction and stronger reinstatement of cocaine conditioned place preference in adolescent rats, compared to adults. Behav Neurosci 122: 460-465.

Brown PL, Jenkins HM. 1968. Auto-shaping of the pigeon's key-peck. J Exp Anal Behav 11: 1-8.

Conklin CA. 2006. Environments as cues to smoke: Implications for human extinction-based research and treatment. Exp Clin Psychopharmacol 14: 12-19.

Cunningham CL, Zerizef CL. 2014. Effects of combining tactile with visual and spatial cues in conditioned place preference. Pharmacol Biochem Behav 124: $443-450$.

D'amato MR, Buckiewicz J. 1980. Long-delay, one-trial conditioned preference and retention in monkeys (Cebus apella). Anim Learn Behav 8: $359-362$.

Diamond ME, von Heimendahl M, Knutsen PM, Kleinfeld D, Ahissar E. 2008. "Where" and "what" in the whisker sensorimotor system. Nat Rev Neurosci 9: 601-612.

Engelmann JM, Gewirtz JC, Cuthbert BN. 2011. Emotional reactivity to emotional and smoking cues during smoking abstinence: Potentiated startle and P300 suppression. Psychophysiology 48: 1656-1668.

Farwell BJ, Ayres JJB. 1979. Stimulus-reinforcer and response-reinforcer relations in the control of conditioned appetitive headpoking ("goal tracking") in rats. Learn Motiv 10: 295-312.

Filbey FM, Schacht JP, Myers US, Chavez RS, Hutchison KE. 2009. Marijuana craving in the brain. Proc Natl Acad Sci 106: 13016-13021.

Flagel SB, Watson SJ, Akil H, Robinson TE. 2008. Individual differences in the attribution of incentive salience to a reward-related cue: Influence on cocaine sensitization. Behav Brain Res 186: 48-56.

Flagel SB, Akil H, Robinson TE. 2009. Individual differences in the attribution of incentive salience to reward-related cues: implications for addiction. Neuropharmacology 56(Suppl. 1): 139-148.

Flagel SB, Robinson TE, Clark JJ, Clinton SM, Watson SJ, Seeman P, Phillips PEM, Akil H. 2010. An animal model of genetic vulnerability to behavioral disinhibition and responsiveness to reward-related cues: Implications for addiction. Neuropsychopharmacology 35: 388-400.
Franklin TR, Lohoff FW, Wang Z, Sciortino N, Harper D, Li Y, Jens W, Cruz J, Kampman K, Ehrman R, et al. 2009. DAT genotype modulates brain and behavioral responses elicited by cigarette cues. Neuropsychopharmacology 34: 717-728.

Frick KM, Gresack JE. 2003. Sex differences in the behavioral response to spatial and object novelty in adult C57BL/6 mice. Behav Neurosci 117: $1283-1291$.

Grant S, London ED, Newlin DB, Villemagne VL, Liu X, Contoreggi C, Phillips RL, Kimes AS, Margolin A. 1996. Activation of memory circuits during cue-elicited cocaine craving. Proc Natl Acad Sci 93: 12040-12045.

Guterl SA, McNamara TA, Klumpp GC, Meerts SH. 2015. Female rats express a conditioned object preference for receipt of sexual stimulation. Physiol Behav 151: 320-326.

Kaun KR, Azanchi R, Maung Z, Hirsh J, Heberlein U. 2011. A Drosophila model for alcohol reward. Nat Neurosci 14: 612-619.

Kennedy BC, Dimova JG, Siddappa AJM, Tran PV, Gewirtz JC, Georgieff MK. 2014. Prenatal choline supplementation ameliorates the long-term neurobehavioral effects of fetal-neonatal iron deficiency in rats. J Nutr 144: 1858-1865.

Miller NE. 1961. Analytical studies of drive and reward. Am Psychol 16: $739-754$.

Myrick H, Anton RF, Li X, Henderson S, Randall PK, Voronin K. 2008. Effect of naltrexone and ondansetron on alcohol cue-induced activation of the ventral striatum in alcohol-dependent people. Arch Gen Psychiatry 65: $466-475$.

Nees F, Diener C, Smolka MN, Flor H. 2012. The role of context in the processing of alcohol-relevant cues. Addict Biol 17: 441-451.

Ninkovic J, Bally-Cuif L. 2006. The zebrafish as a model system for assessing the reinforcing properties of drugs of abuse. Methods 39: 262-274.

Oliveira AMM, Hawk JD, Abel T, Havekes R. 2010. Post-training reversible inactivation of the hippocampus enhances novel object recognition memory. Learn Mem 17: 155-160.

Palchykova S, Winsky-Sommerer R, Meerlo P, Dürr R, Tobler I. 2006. Sleep deprivation impairs object recognition in mice. Neurobiol Learn Mem 85: $263-271$.

Pavlov I. 1932. The reply of a physiologist to psychologists. Psychol Rev 39: $91-127$.

Peartree NA, Hood LE, Thiel KJ, Sanabria F, Pentkowski NS, Chandler KN, Neisewander JL. 2012. Limited physical contact through a mesh barrier is sufficient for social reward-conditioned place preference in adolescent male rats. Physiol Behav 105: 749-756.

Powell J, Gray J, Bradley B. 1993. Subjective craving for opiates: Evaluation of a cue exposure protocol for use with detoxified opiate addicts. $\mathrm{Br} J$ Clin Psychol 32: 39-53.

Rescorla R, Wagner A. 1972. A theory of Pavlovian conditioning: Variations in the effectiveness of reinforcement. In Classical conditioning II: Current research and theory (ed. Black AH, Prokasy WF), Vol. 2, pp. 64-99. Appleton-Century-Crofts, New York.

Schechter MD, Calcagnetti DJ. 1993. Trends in place preference conditioning with a cross-indexed bibliography; 1957-1991. Neurosci Biobehav Rev 17: 21-41.

Spyraki C, Fibiger HC, Phillips AG. 1982. Cocaine-induced place preference conditioning: Lack of effects of neuroleptics and 6-hydroxydopamine lesions. Brain Res 253: 195-203.

Sullivan JC, Mitchinson B, Pearson MJ, Evans M, Lepora NF, Fox CW, Melhuish C, Prescott TJ. 2012. Tactile discrimination using active whisker sensors. IEEE Sens J 12: 350-362.

Thewissen R, Snijders SJBD, Havermans RC, van den Hout M, Jansen A. 2006. Renewal of cue-elicited urge to smoke: Implications for cue exposure treatment. Behav Res Ther 44: 1441-1449.

Tzschentke TM. 2007. Measuring reward with the conditioned place preference (CPP) paradigm: Update of the last decade. Addict Biol 12: $227-462$.

Williams DR, Williams H. 1969. Auto-maintenance in the pigeon: Sustained pecking despite contingent non-reinforcement. J Exp Anal Behav 12: 511-520.

Wilson SJ, Sayette MA, Fiez JA. 2012. Quitting-unmotivated and quitting-motivated cigarette smokers exhibit different patterns of cue-elicited brain activation when anticipating an opportunity to smoke. J Abnorm Psychol 121: 198-211.

Received April 9, 2016; accepted in revised form July 28, 2016. 


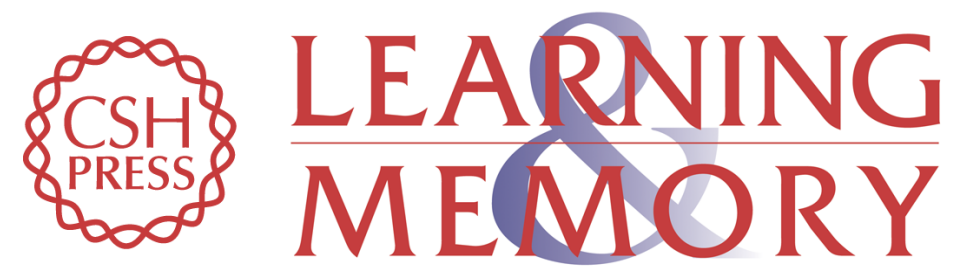

\section{Conditioned object preference: an alternative approach to measuring reward learning in rats}

Bruce C. Kennedy, Maulika Kohli, Jamie J. Maertens, et al.

Learn. Mem. 2016, 23:

Access the most recent version at doi:10.1101/Im.042598.116

\section{Supplemental http://learnmem.cshlp.org/content/suppl/2016/10/06/23.11.623.DC1 Material}

References This article cites 44 articles, 5 of which can be accessed free at: http://learnmem.cshlp.org/content/23/11/623.full.html\#ref-list-1

Creative This article is distributed exclusively by Cold Spring Harbor Laboratory Press for the Commons first 12 months after the full-issue publication date (see

License http://learnmem.cshlp.org/site/misc/terms.xhtml). After 12 months, it is available under a Creative Commons License (Attribution-NonCommercial 4.0 International), as described at http://creativecommons.org/licenses/by-nc/4.0/.

Email Alerting Receive free email alerts when new articles cite this article - sign up in the box at the Service top right corner of the article or click here. 